\title{
Detection of Mitochondrial DNA T16189C Polymorphism
}

\author{
Nihad A.M. Al-Rashedi ${ }^{1}$, Emad Uldeen Hateem ${ }^{2}$ \\ ${ }^{1,2}$ Biology Department - College of Science - Muthanna University
}

\begin{abstract}
This study can be observed as polymorphic nucleotide where $T$ to $C$ transition was observed at the 16189 nucleotide position in mitochondrial DNA. The aim of this study was to confirm to the mtDNA polymorphic nucleotide which may be useful in the forensic genetics and clinical applications. The 100 blood samples of Iraqi population were collected for mitochondrial DNA extraction and evaluated for mtDNA 16189 variant by PCR-RFLP technique. Then, digested fragments were ready to direct DNA sequencing. The results showed that detection of transition $T$ to $C$ at the position 16189 in mitochondrial DNA by PCR-RFLP and direct DNA sequencing. The frequency of transitional polymorphic nucleotides at positions 16189 were 0.16 observed highest. It is transition generates heteroplasmic length tract of polycytosine which has advantage in mitochondrial DNA fingerprinting and index of different metabolic disorders.
\end{abstract}

Keywords: mtDNA polymorphism, T16189C, PCR-RFLP, DNA Sequencing

\section{Introduction}

The non-coding region of mitochondrial DNA (mtDNA) has the polymorphic positions, so that forensic investigations which are mostly focus on control region of mtDNA as genetic markers in human identity testing (1). The position 16189 in mtDNA record in Arab Iraqi population as forensic marker (2).

On other side, there were many studies proved that mutations in mtDNA linked to the occurrence of several systemic diseases in humans, although these studies proved this relationship but it remains without reason or access to the mechanism of interdependence between these diseases and non-coding mtDNA mutations. One of the hot spot mutations 16189 which have importance to generated genotypes of mitochondria DNA through heteroplasmy length variation (3).

\section{Methods}

The present study was randomly selected hundred blood samples of unrelated Iraqi volunteers of three sequential generations. Mitochondrial DNA was isolated by using mtDNA extraction Kit (Biovision, USA). PCR amplification of the mtDNA performed by forward primer L15911 (15911 15930), 5ACCAGTCTTGTAAACCGGAG- 3 and reverse primer H16540 (16540-16521), 5-GTGGGCTATTTAGGCTTT AT-3 (4). The amplification reaction included $10 \mu \mathrm{l}$ of $5 \mathrm{X}$ KAPA HiFi buffer and $1.5 \mu \mathrm{l}$ of $10 \mathrm{mM}$ KAPA dNTP was mixed with $1 \mu$ of KAPA HiFi Hot Start DNA Polymerase (1U/ $\mu \mathrm{l})$ to $200 \mu \mathrm{l}$ labeled PCR tubes labeled. Added $3 \mu \mathrm{l}$ of $10 \mu \mathrm{M}$ Primer Pair (forward and reverse primer) . The volume was completed to $46.5 \mu \mathrm{l}$ and then , added $4.5 \mu \mathrm{l}$ human mtDNA to each tube, then gently pipette the entire volume up and down 10 times to mix thoroughly. The tubes were run in programmed thermal cycler (MultiGene optiMax, USA) included $95^{\circ} \mathrm{C}$ for 3 min and 35 cycles of $98{ }^{\circ} \mathrm{C}$ for 20 sec., $59{ }^{\circ} \mathrm{C}$ for $15 \mathrm{sec}$, and $72{ }^{\circ} \mathrm{C}$ for 20 sec. PCR products were digested with $1 \mathrm{U}$ of the Mn1I enzyme and incubated at $37 \stackrel{\circ}{\mathrm{C}}$ for 1 hour in total reaction volume of $50 \mu \mathrm{l}$ according to the manufacturer's instructions ( Biolab, USA). Digested products were showed by agarose electrophoresis in 3\% agarose gels $70 \mathrm{v}$. for $60 \mathrm{~min}$. The restriction site was at position 16189 will giving two band sizes $351 \mathrm{bp}$ and $278 \mathrm{bp}$. In the mutant type was no cut in the restriction site will giving band size 629bp. The digested products were subjected to cycle sequencing by using $\mathrm{ABI}$ 3730 xL DNA analyzer (Applied Biosystem, USA). The DNA Sequence Data were analyzed by using BioEdit Software and then aligned with the revised Cambridge Reference Sequence (GenBank sequence NC_012920) by added the CLUSTAL $\mathrm{W}$ to the same software.

\section{Results and Discussion}

The length heteroplasmy is most common form of heteroplasmy observed in mtDNA control region. The mtDNA sequence of individuals differs in length by single nucleotide, usually cytosine residue in homoplasmic tracts compared to Cambridge reference sequence. The major form of length heteroplasmy is observed at moderate frequency which is depend on frequency of the 16189 transition from $\mathrm{T}$ to C about (20\%) (5).

The analysis of non-coding mitochondrial DNA 16189 variant has forensic and medical importance. The sequence variations within mtDNA non-coding regions have forensic value, where mutation rate of mtDNA control region is about 5 to 10 times higher than nuclear DNA, so that this region among unrelated individuals has been estimated to vary 1-3\% (6), in this study, that samples at position 16189 is regarded special feature help improved data interpretation and probability of match (7).

On other hand, The T16189C variant in human mitochondrial DNA (mtDNA) have been associated with disease, One report was suggested that relation between 16189 variant and diabetic type 2 and insulin resistance due to mitochondrial function through 16189 polymorphic effect on mtDNA replication (8). 


\section{International Journal of Science and Research (IJSR) \\ ISSN (Online): 2319-7064 \\ Index Copernicus Value (2013): 6.14 | Impact Factor (2015): 6.391}

Length heteroplasmy was detected in Iraqi samples by PCR-RFLP and direct sequencing of the mtDNA T16189C position which result in a polycytosine tract. Heteroplasmic $\mathrm{T}$ and $\mathrm{C}$ at this specific position is not enough to be detected by direct sequencing, in spite of the quality score of this position which approved confirmatory results of this heteroplasmic point mutation the light and heavy strand examination was carried out, so that these results supported by PCR-RFLP technique. The presence of the 16189 variant of mtDNA was determined using the PCR-restriction fragment length polymorphism T16189C by the enzyme Mn1I as shown in figure (1).

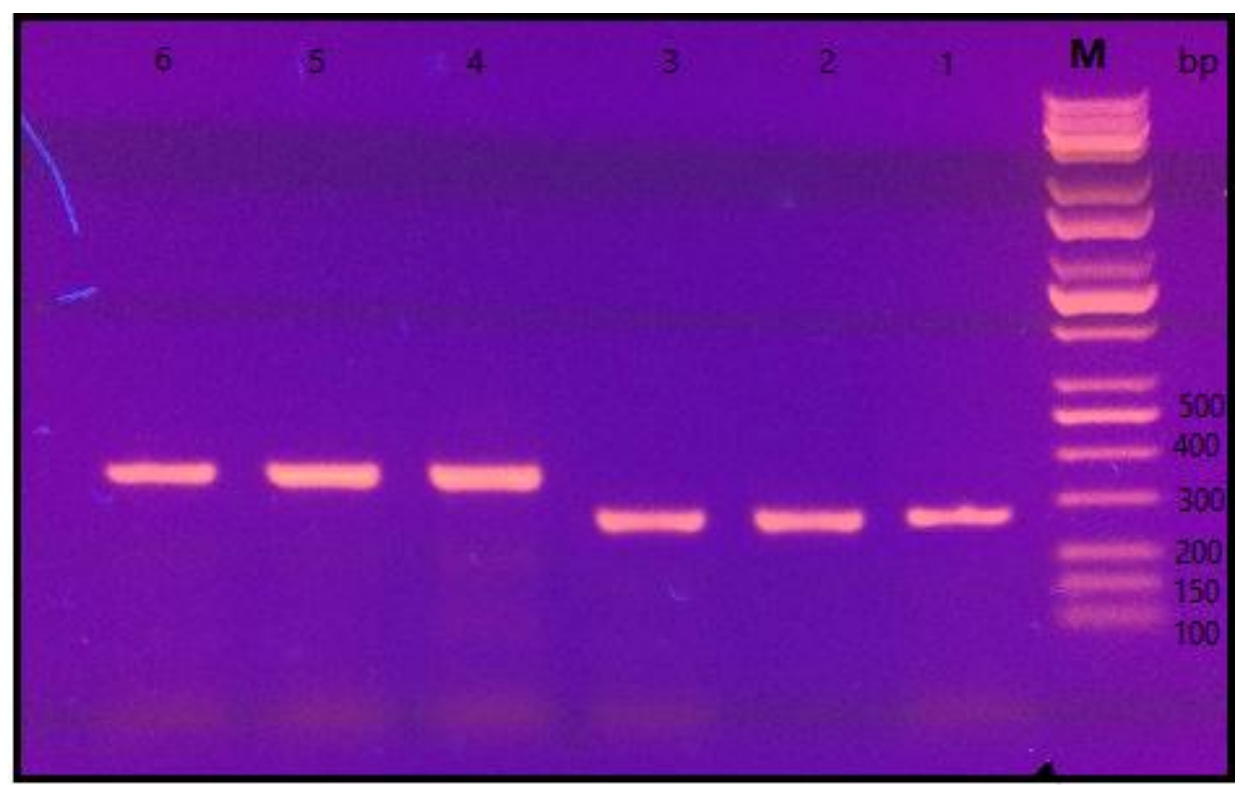

Figure 1: The 16189 variant of mtDNA was determined using the PCR-RFLP T16189C by the enzyme Mn1I

In this study, the DNA sequencing data alignment for both light and heavy strand covered important C-stretch regions between 16184 to 16193 has good reading upstream of Cstretch region (9). The longest C-stretch region observed within the 16 samples contained 10 serial cytosine residues, occurred by nucleotide transition at position 16189 as shown in Figure (2). The important topics in forensic genetics investigation are C-stretches regions which include the sequence spans nucleotides position 16184 to 16193 by change $\mathrm{T}$ at position 16189 according to Cambridge reference sequence. This transition is from $\mathrm{T}$ to $\mathrm{C}$ in the samples which produce homopolymeric C-stretch due to polymerases slippage that rise errors in complementary strand synthesis to the mtDNA template. The length variant of homopolymeric cytosine can lead to heteroplasmic length variation in the control region of mtDNA which considered a power of discrimination in forensic mtDNA investigation (7).

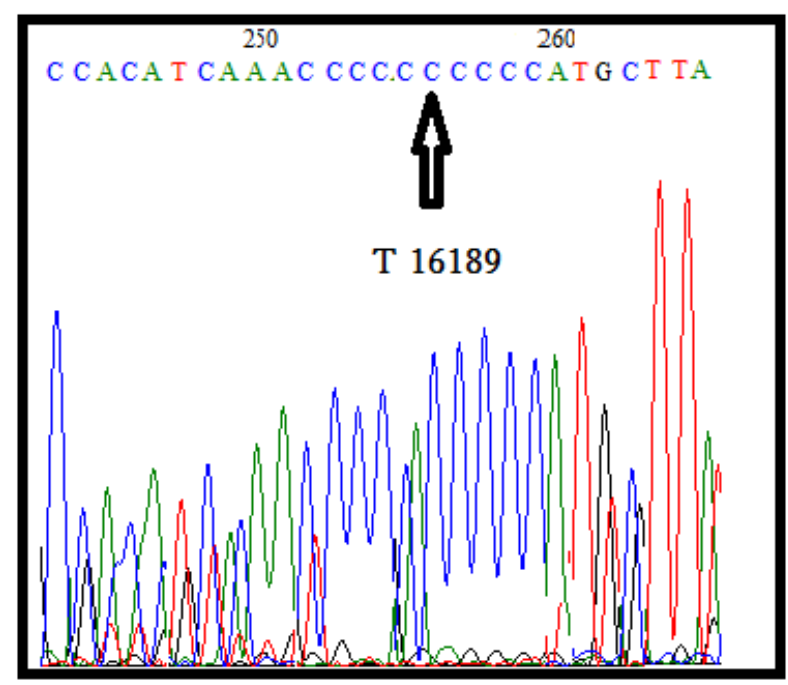

Figure 2: DNA sequencing data illustrate $\mathrm{C}$-stretch region occurs when $\mathrm{T}$ transited to $\mathrm{C}$ at position 16189.

However, the main reason for the occurrence of these variations is the low efficiency of repair and the production of replication error in the non-coding region, so that these variations have suitable as forensic genetic marker (10). The $\mathrm{T}$ to $\mathrm{C}$ transition at 16189 position forms polycytosine tract which lead to heteroplasmic length variation in the control region of mtDNA due to in the regulatory D-loop may exposed to the mtDNA to errors of replication (3). 


\section{References}

[1] Holland, M.M and Parsons T.J. (1999) Mitochondrial DNA sequence analysis - Validation and use for forensic casework. Forensic Sci Rev.;11:21-50.

[2] Al-Rashedi, N.A.M., Jebor, M.A. and Mousa T.AH. (2016) Mitochondrial DNA Markers in Arabic Iraqi Population Eur. J Forensic Sci. 2016; 3(3): 1-

[3] Marchington, D.R.; Poulton, J.; Sellar, A. and Holt, I.J. (1996) Do sequence variants in the major noncoding region of the mitochondrial genome influence mitochondrial mutations associated with disease? Human Molecular Genetics;5(4): 473-479.

[4] Weng, SW.; Liou, CW.; Lin, TK. et al.(2005) Association of Mitochondrial Deoxyribonucleic Acid 16189 Variant (T3C Transition) with Metabolic Syndrome in Chinese Adults. The Journal of Clinical Endocrinology \& Metabolism 90(9):5037-5040.

[5] Melton, T.(2004)Mitochondrial DNA Heteroplasmy. Forensic Sci. Rev., 16(1):1-20.

[6] Piercy, R.; Sullivan, K.M.; Benson, N. and Gill, P. (1993) The application of mitochondrial DNA typing to the study of white Caucasian genetic identification. International Journal of Legal Medicine,106:85-90

[7] Bendall, K.E. and Sykes, B.C. (1995) Length heteroplasmy in the first hypervariable segment of the human mtDNA control region. Am J Hum Genet.; 57(2):248-56.

[8] Poulton, J.; Luan, J.; Macaulay, V.; Hennings, S.; Mitchell, J. and Wareham, N.J. (2002) Type 2 diabetes is associated with a common mitochondrial variant: evidence from a population-based case-control study. Human Molecular Genetics, 11(13): 1581-1583.

[9] Stewart, J. E. B.; Fisher, C. L.; Aagaard, P. J.; Wilson, M. R.; Isenberg, A. R.; Polanskey, D.; Pokorak, E.; DiZinno, J. A. and Budowle, B. (2001) Length variation in HV2 of the human mitochondrial DNA control region. J. Forensic Sciences; 46:862-870.

[10] Wilson, M. R., Stoneking, M., Holland, M. M, DiZinno, J. A. and Budowle, B. (1993) Guidelines for the use of mitochondrial DNA sequencing in forensic science. Crime Laboratory Digest, 20, 68-77. 